\title{
Clinical significance of plasma adrenaline and noradrenaline concentrations in patients with subarachnoid haemorrhage
}

\author{
C.R. B E N E D I C T ${ }^{1}$ A N D A.B. L O A C H \\ From the Medical Research Council Unit and Department of Clinical Pharmacology, and the \\ Nuffield Department of Anaesthetics, University of Oxford
}

S U M M A R Y Plasma adrenaline and noradrenaline concentrations were measured in 21 patients after subarachnoid haemorrhage and in 13 control patients. Plasma noradrenaline concentrations were significantly raised in patients recovering from subarachnoid haemorrhage, confirming clinical evidence of overactivity of the sympathetic nervous system. Plasma noradrenaline concentrations in patients with a poor result were significantly higher at the time of admission than in patients with a good result, and the differences became more significant two to three days later. Therefore, the measurement of plasma noradrenaline concentrations may be a valuable test to assist clinical assessment in distinguishing between the two groups preoperatively.

There is indirect evidence of autonomic nervous system dysfunction after subarachnoid haemorrhage. In the hours after a subarachnoid haemorrhage systemic hypertension is common, and electrocardiographic changes suggestive of myocardial ischaemia or even frank infarction, which have been interpreted as evidence of overactivity of the sympathetic nervous system, have been reported (Weintraub and McHenry, 1974). Greenhoot and Reichenbach (1969) reported six fatal cases of subarachnoid haemorrhage in which recent subendocardial haemorrhages and myofibrillar degeneration were evident at postmortem examination, while Smith and Tomlinson (1954) found subendocardial haemorrhage in 29 of a series of 235 patients at necropsy; such changes have been produced in experimental animals by the intravenous infusion of noradrenaline (Szakaćs and Mehlman, 1960). Plasma catecholamines were measured in man after subarachnoid haemorrhage by Peerless and Griffiths in 1972 using a fluorimetric assay. They found raised plasma catecholamine levels, particularly in patients who were comatose or moribund. How-

${ }^{1}$ Rhodes Scholar.

Address for correspondence and reprint requests: Dr C. R. Benedict, Department of Medicine, Johns Hopkins Medical School, Johns Hopkins Hospital, Baltimore, MD 21205, USA.

Accepted 11 August 1977 ever, they did not measure plasma catecholamine concentrations in a control group of acutely ill patients, and were, therefore, unable to show whether the measured increases in plasma catecholamines were specific to subarachnoid haemorrhage. This paper reports plasma adrenaline and noradrenaline concentrations measured using a more sensitive radioenzymatic method in 21 patients with subarachnoid haemorrhage from a ruptured intracranial aneurysm, and compares them with the concentration found in 13 control patients admitted to hospital for other reasons.

\section{Patients}

SUBARACHNOID HAEMORRHAGE GROUP

Twenty-one non-consecutive patients who did not receive any drugs known to alter plasma catecholamine concentrations were studied. The patients had been referred to the neurosurgical department with a subarachnoid haemorrhage confirmed by obtaining bloodstained cerebrospinal fluid on lumbar puncture. The presence of one or more intracranial aneurysms was demonstrated by angiography, and all the patients were considered suitable for eventual neurosurgery. They were awake, or drowsy with no major neurological deficit (Botterell grade 1, 2, or 3) (Botterell et al., 1956). None of them was comatose or moribund; 
therefore the group studied was composed of patients making a good recovery from the initial episode of subarachnoid haemorrhage.

The purpose of the study was explained to these patients and their consent obtained. Within 24 hours of admission a venous blood sample was collected for plasma catecholamines, and in 14 of them a further sample was collected two to 12 hours before they underwent surgery or, when they were deferred as unfit for surgery. The time of collection of these samples after subarachnoid haemorrhage is shown in Table 1.

Table 1 Time interval between subarachnoid haemorrhage and collection of first and second blood samples for plasma adrenaline and noradrenaline estimation

\begin{tabular}{|c|c|c|c|c|}
\hline Patients & $\begin{array}{l}\text { Botterell } \\
\text { grade at } \\
\text { time of } \\
\text { surgery or } \\
\text { deferment } \\
\text { of surgery }\end{array}$ & $\begin{array}{l}\text { Interval between } \\
\text { subarachnoid } \\
\text { haemorrhage and } \\
\text { collection of } \\
\text { first sample } \\
\text { (days) }\end{array}$ & $\begin{array}{l}\text { Interval between } \\
\text { first and second } \\
\text { sample } \\
(\text { days })\end{array}$ & $\begin{array}{l}\text { Clinical } \\
\text { outcome } \\
\text { of the } \\
\text { patients } \\
\text { at six } \\
\text { weeks }\end{array}$ \\
\hline \multicolumn{5}{|c|}{ Good result group } \\
\hline BW & 1 & 6 & 1 & good \\
\hline JA & 2 & 5 & 1 & good \\
\hline AO & 2 & 5 & 1 & good \\
\hline MHS & 1 & 6 & - & good \\
\hline $\mathbf{M N}$ & 1 & 3 & - & good \\
\hline PB & 3 & 28 & 1 & good \\
\hline MB & 1 & 6 & 10 & good \\
\hline ET & 1 & 24 & 2 & good \\
\hline DW & 2 & 4 & 3 & fair \\
\hline HP & 2 & 8 & 1 & fair* \\
\hline \multicolumn{5}{|c|}{ Poor result group } \\
\hline PC & 2 & 3 & 3 & poor \\
\hline LB & 2 & 8 & 1 & poor \\
\hline EG & 1 & 6 & 1 & poor \\
\hline AC & $2 \dagger$ & 7 & - & poor \\
\hline EB & $3 \dagger$ & 9 & - & poor \\
\hline $\mathbf{K S}$ & $2 \dagger$ & 3 & - & poor \\
\hline DVI & $2 \dagger$ & 10 & 6 & poor \\
\hline RG & 2 & 3 & 25 & died \\
\hline IG & 2 & 3 & 3 & died \\
\hline WH & 3 & 8 & 1 & died \\
\hline AG & $3 \dagger$ & 17 & 10 & died \\
\hline
\end{tabular}

*Subsequently died of myocardial infarction †Surgery deferred

Six weeks after neurosurgery the clinical state of the patients was assessed using the method of Loach and de Azevedo (1976). The "good result" group consisted of patients whose clinical state was good (back at work), or fair (independent, but unable to return to their original work because of a residual neurological deficit), while those who were poor (still needed help in daily life) or had died were called the "poor result" group. The patients for whom surgery was deferred because of a deteriorating neurological state were included in the "poor result" group.
CONTROL GROUP

The control group consisted of two types of patients. (a) Six patients who were admitted for cardiac catheterisation for investigation of a cardiac murmur but who were not in cardiac failure or taking any drugs. A venous blood sample for estimation of plasma catecholamines was obtained from these patients within two hours of admission and another just before their discharge after 60 72 hours stay in hospital. (b) Seven patients who were admitted with one of the following acute clinical problems: lobar pneumonia, acute appendicitis (three patients), urinary tract infection and cystitis, systemic lupus erythematosus accompanied by fever, and pleurisy. Blood samples were collected from these patients within two hours of admission and three or four days later when their acute symptoms were gradually subsiding.

\section{Methods}

All blood samples were taken from an antecubital vein, after at least $30 \mathrm{~min}$ of quiet supine bed rest, into a lithium heparin tube containing solid reduced glutathione as the antioxidant, and placed in ice. They were immediately centrifuged at $2000 \mathrm{~g}$ at $4^{\circ}$ for five minutes, and the plasma separated and stored at $-20^{\circ}$. The samples were assayed within five to six days of collection in duplicate by the method of Hörtnagl et al. (1977). The data were analysed using Student's two-tailed unpaired $t$ test.

\section{Results}

There was no significant difference between the ages (27-64 years; 24-64 years) and sexes (M 9 : F 11; M 6: F 7) of the patients in the subarachnoid haemorrhage group and the control group.

Plasma adrenaline concentrations in the patients with subarachnoid haemorrhage were raised and significantly greater than the concentrations in patients admitted for cardiac catheterisation $(\mathrm{P}<0.02)$ (Table 2). However, the plasma adrenaline concentrations in patients with subarachnoid haemorrhage were not significantly greater than those of the patients in subgroup (b) with other pathology.

Plasma noradrenaline concentrations in patients with subarachnoid haemorrhage were very much greater than the concentrations found both in the cardiac catheterisation subgroup $(\mathrm{P}<0.005)$ and in the subgroup of patients with other pathology $(\mathrm{P}<0.01)$ (Table 2).

When the patients with subarachnoid haemorrhage were subdivided into a "good result" group 
Table 2 Plasma adrenaline $(A)$ and noradrenaline $(N A)$ concentrations in subarachnoid haemorrhage and control group of patients at the time of admission and on re-cvaluation (mean \pm sem)

\begin{tabular}{|c|c|c|c|c|c|c|}
\hline & & \multicolumn{3}{|c|}{ Subarachnoid haemorrhage } & \multicolumn{2}{|l|}{ Control grcup } \\
\hline & & $\begin{array}{l}\text { All the patients } \\
\text { as a group } \\
(n=2 I)\end{array}$ & $\begin{array}{l}\text { Good prognosis } \\
\text { group } \\
(n=2 I)\end{array}$ & $\begin{array}{l}\text { Poor prognosis } \\
\text { group } \\
(n=I I)\end{array}$ & $\begin{array}{l}\text { Subgroup a } \\
\text { Cardiac } \\
\text { catheterisation } \\
(n=6)\end{array}$ & $\begin{array}{l}\text { Subgroup b } \\
\text { Patients with } \\
\text { other illnesses } \\
(n=7)\end{array}$ \\
\hline $\begin{array}{l}\text { Plasma } \\
\text { adrenaline } \mathrm{ng} / \mathrm{ml}\end{array}$ & $\begin{array}{l}\text { On admission } \\
\text { On re-evaluation }\end{array}$ & $\begin{array}{c}0.65 \pm 0.11 \\
-\end{array}$ & $\begin{array}{l}0.41 \pm 0.08 \\
0.30 \pm 0.06 \\
(n=7)\end{array}$ & $\begin{array}{l}0.87 \pm 0.17 \\
0.92 \pm 0.24 \\
(n=7)\end{array}$ & $\begin{array}{l}0.14=0.04 \\
0.15 \pm 0.03\end{array}$ & $\begin{array}{l}0.53 \pm 0.07 \\
0.19 \pm 0.03\end{array}$ \\
\hline \multirow{2}{*}{$\begin{array}{l}\text { Plasm } \mathrm{i} \\
\text { noradrenaline } \\
\mathrm{ng} / \mathrm{ml}\end{array}$} & On admission & $0.94+0.10$ & $0.68 \pm 0.12$ & $1.14 \doteq 0.12$ & $0.29 \pm 0.02$ & $0.44 \pm 0.04$ \\
\hline & On re-evaluation & & $\begin{array}{l}0.46+0.07 \\
(n=7)\end{array}$ & $\begin{array}{l}1.25+0.16 \\
(n=7)\end{array}$ & $0.30 \pm 0.02$ & $0.35 \pm 0.01$ \\
\hline
\end{tabular}

Normal values (mean \pm sem) for this laboratory $\left\{\begin{array}{l}A=0.13 \pm 0.02 \mathrm{ng} / \mathrm{ml} \\ N A=0.48 \pm 0.03 \mathrm{ng} / \mathrm{ml}\end{array}\right.$

The normal values for catecholamines in this laboratory were obtained by measuring plasma adrenaline and noradrenaline in 18 healthy subjects (M 11: F 7) aged 21-70 years, from whom a peripheral venous blood sample was collected after 30 min supine bed rest.

and a "poor result" group further differences were apparent, particularly in plasma noradrenaline concentrations (Table 2). In patients with a good result, plasma noradrenaline concentrations were raised on admission but were not significantly different from those of patients with other pathology. In the poor result group plasma noradrenaline concentrations were markedly increased and significantly higher than the concentrations in patients with other pathology $(\mathrm{P}<0.001)$, and in the patients with subarachnoid haemorrhage and a good result $(\mathrm{P}<0.01)$ (Fig. 1).

The plasma concentrations of adrenaline and noradrenaline after a period of bed rest of at least

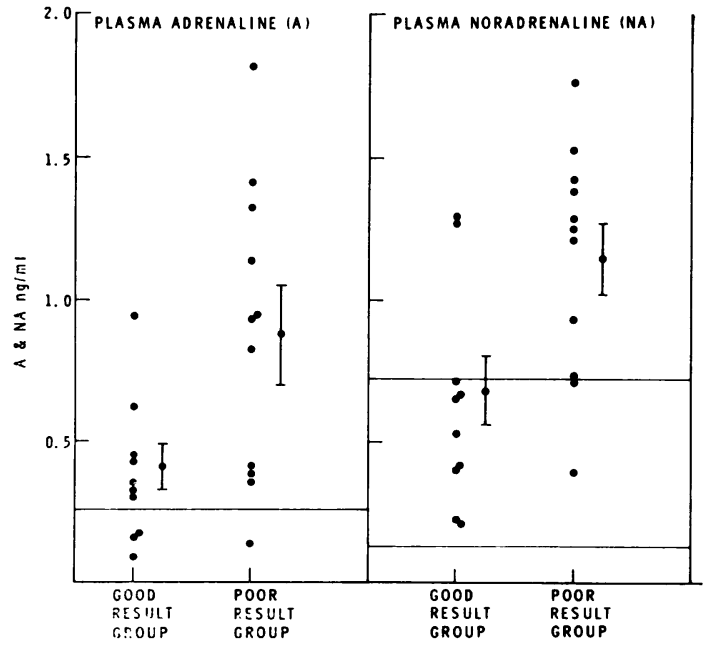

Fig. 1 Plasma adrenaline and noradrenaline concentrations on admission in the good and poor prognosis patients after subarachnoid haemorrhage.
24 hours show a greater difference between the poor result and the good result groups. The changes in the concentrations of plasma adrenaline and noradrenaline with time between admission and surgery or deferment of surgery are given in Fig. 2. On re-evaluation, the plasma

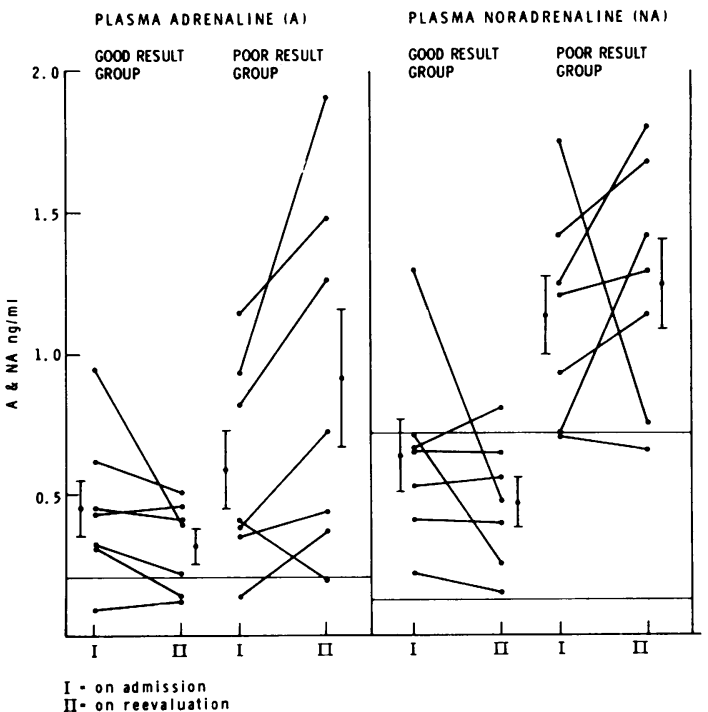

Fig. 2 Changes in plasma adrenaline and noradrenaline concentrations with time in good and poor prognosis patients.

adrenaline concentrations in the poor result group had increased and become significantly different from all the other groups $(P<0.05)$. Similarly, in the same group of patients plasma noradrenaline 
concentrations showed a further rise from already significantly increased initial concentrations. In all the other patients there was a decline in both plasma adrenaline and noradrenaline concentration.

\section{Discussion}

The significance of these results is twofold. Firstly, at the time of admission after a subarachnoid haemorrhage there are increased circulating concentrations of plasma adrenaline and noradrenaline (Table 1). Since the increase in plasma adrenaline is similar to that in subgroup (b) of the control group of patients, this rise is probably not specifically due to subarachnoid haemorrhage. However, the increased plasma noradrenaline concentrations are significantly different from the concentrations in both control subgroups of patients, indicating that there is increased sympathetic nervous system activity in the patients with subarachnoid haemorrhage. Although it is difficult to know just how much noradrenaline released from the sympathetic postganglionic nerve endings escapes neuronal and extraneuronal uptake and metabolism to enter the plasma, other workers have used plasma noradrenaline concentrations as an index of sympathetic nervous system activity (Von Euler, 1964; Mathias et al., 1976). These increased concentrations are in accord with clinical observations which have been interpreted as evidence of increased sympathetic nervous system activity such as systemic hypertension and ischaemic electrocardiographic changes (Greenhoot and Reichenbach, 1969; Weintraub and McHenry, 1974).

The mechanism of sympathetic nervous system activation after subarachnoid haemorrhage is obscure. It is possible that this activation originates in the hypothalamus, and Hammermeister and Reichenbach (1969) reported a patient with transmural myocardial infarction after subarachnoid haemorrhage who also had pyknosis and chromatolysis of cells of the hypothalamus: in experimental animals hypothalamic stimulation may produce electrocardiographic changes similar to those described in humans after subarachnoid haemorrhage (Melville et al., 1963). The blood supply of the hypothalamus is through fine perforating vessels arising from the internal carotid arteries and the posterior communicating arteries and the proximal part of the anterior cerebral arteriesall common sites for intracranial aneurysms. Rupture of an aneurysm which disrupts these fine vessels or leads to vasospasm of the main trunk could diminish hypothalamic blood supply leading to damage, alteration in hypothalamic function and increase in peripheral sympathetic nervous system activity.

Since there appears to be good evidence of sympathetic nervous system activity in these patients, early consideration might be given to the use of $\beta$-adrenergic blocking agents to prevent myocardial damage, particularly if the patient has electrocardiographic abnormalities or is hypertensive.

Secondly, at the time of admission the patients with a poor result may be clinically indistinguishable from those with a good result. In the poor result group the plasma noradrenaline concentrations measured at the time of admission or two to three days later differed significantly from the concentrations found in the good result group and in both the control groups of patients (Table 1). Therefore, the measurement of plasma noradrenaline concentrations after admission to hospital may assist clinical assessment in selecting suitable patients for neurosurgrey.

The authors thank Mr C. B. T. Adams and Mr M. Briggs, Department of Neurosurgery, Radcliffe Infirmary, for permission to investigate patients under their care, Professor D. G. Grahame-Smith and Professor A. Crampton-Smith for their encouragement and advice, and Mrs M. E. Harris for typing the manuscript.

\section{References}

Botterell, E. H., Lougheed, W. B., Scott. J. W., and Vanderwater, S. L. (1956). Hypothermia and interruption of carotid or carotid and vertebral circulation in the surgical management of intracranial aneurysms. Journal of Neurosurgery, 19, 1-42.

Greenhoot J. H., and Reichenbach, D. D. (1969). Cardiac injury and subarachnoid hemorrhage. Journal of Neurosurgery, 30, 521-531.

Hammermeister, K. E., and Reichenbach, D. D. (1969). QRS changes, pulmonary oedema and myocardial necrosis associated with subarachnoid hemorrhage. American Heart Journal, 78, 94-100.

Hörtnagl, H., Benedict, C. R., Grahame-Smith, D. G., and McGrath, B. (1977). A sensitive radioenzymatic assay for adrenaline and noradrenaline in plasma. British Journal of Clinical Pharmacology, 4, 553-558.

Loach, A. B., and de Azevedo Filho, H. R. C. (1976). Some observations on the microneurosurgical treatment of intracranial aneurysms. Acta Neurochirurgica, 35, 97-103.

Mathias, C. J.. Christensen, N. H., Corbett, J. L., Frankel, H. L. and Spalding, J. M. K. (1976). Plasma catecholamines during paroxysmal neurogenic hypertension in quadriplegic man. Clinical Research, 39, 204-208. 
Melville, K. J.. Blum, B., Shister, H. E., and Silver, M. D. (1963). Cardiac ischemic changes and arrhythmias induced by hypothalamic stimulation. American Journal of Cardiology, 12, 781-791.

Peerless, S. J., and Griffiths, J. C. (1972). Plasma catecholamines following subarachnoid hemorrhage. Annals of Royal College of Physicians and Surgeons. Canada, 5, 48-49.

Smith, R. P., and Tomlinson, B. E. (1954). Subendocardial haemorrhages associated with intracranial lesions. Journal of Pathology (London), 68, 327-334.

Szakaćs, J. E.. and Mehlman, B. (1960). Pathologic changes incluced by norepinephrine. American Journal of Cardiology, 5, 619-627.

Von Euler, U. S. (1964). Quantitation of stress by catecholamine analysis. Clinical Pharmacology and Therapeutics, 5, 398-404.

Weintraub. B. M., and McHenry, L. C. J. (1974). Cardiac abnormalities in subarachnoid hemorrhage. A resumé. Stroke, 5, 384-392. 